\title{
A phase I clinical trial of adoptive transfer of folate receptor-alpha redirected autologous $T$ cells for recurrent ovarian cancer
}

\author{
Lana E Kandalaft, Daniel J Powell Jr and George Coukos
}

\begin{abstract}
Purpose: In spite of increased rates of complete response to initial chemotherapy, most patients with advanced ovarian cancer relapse and succumb to progressive disease.

Rationale: Genetically reprogrammed, patient-derived chimeric antigen receptor (CAR)-T lymphocytes with the ability to recognize predefined surface antigens with high specificity in a non-MHC restricted manner have shown increasing anti-tumor efficacy in preclinical and clinical studies. Folate receptor-a (FRa) is an ovarian cancer-specific tumor target; however, it is expressed at low levels in certain organs with risk for toxicity.

Design: Here we propose a phase I study testing the feasibility, safety and preliminary activity of FRa-redirected CAR-T cells bearing the CD137 (4-1BB) costimulatory domain, administered after lymphodepletion for the treatment of recurrent ovarian cancer. A novel trial design is proposed that maximizes safety features.

Innovation: This design involves an initial accelerated dose escalation phase of FR-a CAR-T cells followed by a standard $3+3$ escalation phase. A split-dose approach is proposed to mitigate acute adverse events. Furthermore, infusion of bulk untransduced autologous peripheral blood lymphocytes (PBL) is proposed two days after CAR-T cell infusion at the lower dose levels of CAR-T cells, to suppress excessive expansion of CAR-T cells in vivo and mitigate toxicity.
\end{abstract}

\section{Background and rationale}

\section{Adoptive T cell therapy in ovarian cancer}

Ovarian cancer is the fifth most common cancer in women, affecting one of every 55 women. There are about 21,650 new cases annually in the United States, with 15,520 deaths estimated in 2008 [1] making ovarian cancer the most common cause of death from gynecologic malignancy. While there have been improvements in the treatment of epithelial ovarian cancer, most patients present with Stage III or IV disease, which has a 5-year survival rate of less than 25\% [2-4]. New approaches are needed to improve the outcome of these women [5].

Adoptive immunotherapy is one of the most robust forms of immunotherapy for the treatment of established tumors [6]. Early cell transfer trials in ovarian cancer have been promising: In one such trial, administration of autologous tumor-infiltrating lymphocytes

\footnotetext{
* Correspondence: Iknd@mail.med.upenn.edu

Ovarian Cancer Research Center, Perelman School of Medicine at University of Pennsylvania, Philadelphia, PA, USA
}

(c) 2012 Kandalaft et al.; licensee BioMed Central Ltd. This is an Open Access article distributed under the terms of the Creative Commons Attribution License (http://creativecommons.org/licenses/by/2.0), which permits unrestricted use, distribution, and reproduction in any medium, provided the original work is properly cited. and cisplatin chemotherapy resulted in prolonged disease-free survival and increased the 3-year survival rate, supporting the notion that $\mathrm{T}$ cell transfer can actively inhibit ovarian tumor growth [7]. In another study, administration of TILs (alone or in combination with chemotherapy) was shown to induce objective cancer regressions [8]. Although adoptive immunotherapy has much promise, several problems remain to be solved (reviewed in $[5,6,9])$.

One major obstacle facing the field of cancer immunotherapy is the daunting task of breaking tolerance to self-antigens. This can be difficult or impossible if the $\mathrm{T}$ cell receptor (TCR) repertoire has been deleted or rendered non-functional by various post-thymic tolerance mechanisms $[10,11]$. Several strategies for identifying therapeutically effective $\mathrm{T}$ cell clones and expressing the operative heterodimeric TCR in patients' lymphocytes prior to autologous transplant have been tested (reviewed in [12-16]). An alternative strategy to produce 
genetically engineered $\mathrm{T}$ cells is the 'T-body' or chimeric antigen receptor (CAR) [17] approach.

CARs are fusion molecules comprising an extracellular binding domain, typically a single-chain variable-fragment antibody $(\mathrm{scFv})$, containing the $\mathrm{V}_{\mathrm{H}}$ and $\mathrm{V}_{\mathrm{L}}$ chains joined by a peptide linker of about 15 residues in length [18] and intracellular lymphocyte signaling domains such as $\mathrm{CD} 3 \zeta$, CD28, 4-1BB (CD137), which mediate $\mathrm{T}$ cell activation (reviewed in [14]). CARs bypass a common immune evasion mechanism of tumor cells, the downregulation of MHC-I and antigen presentation, and provide unique opportunities to engineer $\mathrm{T}$ cells without $\mathrm{MHC}$ restriction and with potent costimulatory signals.

\section{CAR-T cell therapy targeting FRa}

A large number of CARs targeting diverse tumors have been developed [14]. Although clinical pilot studies are just beginning, the potential of this form of immunotherapy is becoming increasingly obvious. A trial of 11 patients with neuroblastoma treated with CAR-T cells specific for the GD2 ganglioside showed short-term persistence of CARs with some evidence of antitumor effects [19]. In another report, 19 patients were treated with GD2-specific CAR-T cells, and 3 of 11 achieved remission with long-term persistence of the CARs, which appeared to correlate with clinical outcome [20]. Initial reports have also documented remarkable clinical responses in patients with advanced chronic lymphocytic leukemia (CLL) or lymphoma after therapy with CD19-specific CAR-T cells [21-25]. There has been a single study of adoptive transfer of CAR-T cells in ovarian cancer, with specificity directed against folate receptor- $\alpha(F R \alpha)[26]$; while this study demonstrated safety, the results were disappointing, with no clinical tumor responses, most likely due to low expression of the transgenic CAR, and poor persistence of the transferred $\mathrm{T}$ cells.

For the treatment of ovarian cancer, an appropriate target is the FR $\alpha$, a membrane protein, which binds folic acid with high affinity and mediates the cellular uptake of this vitamin (and drug conjugates thereof) via receptor-mediated endocytosis [27]. Subsequent analyses have shown elevated FR $\alpha$ expression in approximately $90 \%$ of ovarian carcinomas, as well as, numerous other cancers, including endometrial, kidney, lung, mesothelioma, breast, brain, and myeloid leukemia, whereas most normal tissues express low to negligible levels [28]. This could be of clinical significance, particularly given the current development of folate-targeted imaging and therapeutic agents [29]. Low-level FR $\alpha$ expression in normal human tissues is limited to the luminal surface of cells located in the bronchial epithelium, renal tubules and the choroid plexus, intestinal brush-border membranes, type- 1 and type- 2 pneumocytes of the lung, and placental tissue. These folate receptors remain inaccessible to folate and folate conjugates because of their exclusive localization on the apical surfaces of polarized epithelia, and consequently, in healthy patients that do not have malignant masses or an inflammatory disease, measurable folate conjugate uptake has been limited to the kidneys where folate salvage occurs [30]. Renal toxicity has not been observed in animals or humans treated with folate-chemotherapeutic agent conjugates [31,32], antibodies [33] or directed $\mathrm{T}$ cells [26,34], however the acute, transient toxicities associated with administration of anti-folates, such as methotrexate, bear consideration. To date, various folate-drug conjugates have demonstrated safety and therapeutic value in animals $[8,35]$ and in phase-I trials [30]. Promising pilot efficacy data of treating ovarian cancer patients with FR $\alpha$ directed $\mathrm{T}$ cells was provided by a study of adoptive, intraperitoneal (IP) transfer of armed autologous T cells retargeted to FR $\alpha$ using a bispecific monoclonal antibody containing anti-CD3 and anti-FR $\alpha$ MOv18 $\mathrm{F}\left(\mathrm{ab}^{\prime}\right) 2$ fragments, in combination with IP interleukin-2 (IL-2) [34]. The overall intraperitoneal response rate was $27 \%$, with three complete responses lasting 26, 23 and 18 months, respectively. Adverse events included grade 1-2 fever, nausea, emesis and fatigue, which appeared related to IL-2 administration and not to FR $\alpha$ targeting. In the first reported clinical trial of CAR therapy, administration of T cells transduced with a MOv18 scFv-directed FR $\alpha$-specific CAR harboring no costimulatory domains resulted in poor persistence of transferred $\mathrm{T}$ cells in immunocompetent recipients in vivo [26]. While this study demonstrated safety, the results were disappointing, with no clinically evident tumor responses.

In the proposed study, we will test the safety and efficacy of lymphodepletion followed by adoptive transfer of autologous $\mathrm{T}$ cells transduced with CAR recognizing the $\mathrm{FR} \alpha$, and carrying the $\mathrm{CD} 3 \zeta$ domain along with the 4-1BB costimulatory signaling domain to address the issue of persistence of FR $\alpha$-specific CAR-T cells. This CAR construct was developed by Powell and colleagues and was tested in an animal model [35]. Preclinical results show clearly that the anti-FR $\alpha$ CAR outfitted with intracellular $\mathrm{CD} 3 \zeta$ and 4-1BB costimulatory signaling overcomes issues of poor $\mathrm{T}$ cell persistence and tumor localization that limited the previous FR $\alpha$ CAR-T cell targeting strategy, to provide potent antitumor activity in vivo [35]. CARs containing the FR $\alpha$-specific scFv MOv19 coupled to the $\mathrm{T}$ cell receptor $\mathrm{CD} 3 \zeta$ chain signaling module alone (MOv19- $\zeta)$ or in combination with the 4-1BB (CD137) costimulatory motif in tandem (MOv19-BBל) were directly compared (summarized in Figure 1). Primary human T cells that were stably transduced with recombinant lentivirus to express a first generation MOv19- $\zeta$ or second generation costimulated MOv19-BB $\zeta$ CAR secreted various proinflammatory cytokines and exerted cytotoxic function when 


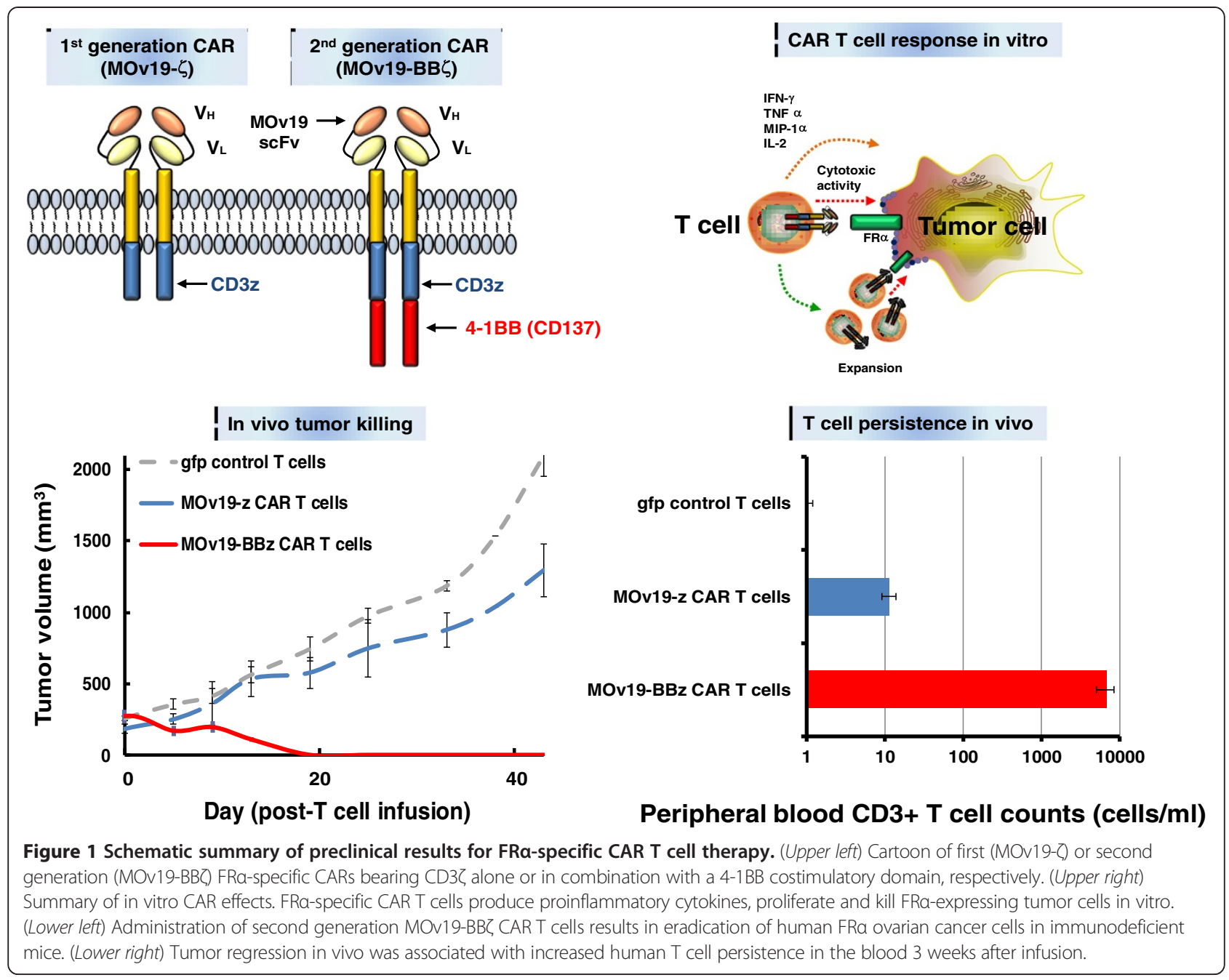

cocultured with FR $\alpha$-positive tumor cells in vitro. However, only transfer of human T cells expressing the costi-

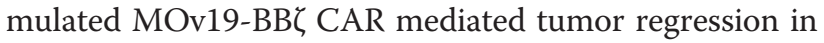
immunodeficient mice bearing large, established $F R \alpha-$ positive human ovarian cancers, while MOv19- $\zeta$ CAR-T cells were ineffective, recapitulating previous clinical results with FR $\alpha$ CAR T cells lacking costimulatory signals. MOv19-BB $\zeta$ CAR-T cell infusion mediated tumor regression in models of metastatic intraperitoneal, subcutaneous, and lung-involved human ovarian cancer. Importantly, tumor response was associated with the selective survival and tumor localization of human $\mathrm{T}$ cells in vivo, and was only observed in mice receiving costimulated MOv19-BB $\zeta$ CAR-T cells. These compelling data warrant the translation to the clinic, and led us to design the following phase I protocol.

\section{Trial design}

This is a phase I, single-arm, single-center, dose-escalation study to establish the safety and proof of concept of autologous FR $\alpha$-redirected $\mathrm{T}$ cells administered intravenously in subjects with recurrent stage II to IV FR $\alpha$-positive epithelial ovarian carcinoma. Subjects will be 18 years or older diagnosed with advanced ovarian cancer who have failed two or more prior chemotherapy regimens, with ECOG $\leq 2$ performance status, and $>3$ month expected survival.

This design involves an initial accelerated doseescalation phase followed by a standard $3+3$ escalation phase. In the initial accelerated phase, cohorts of one subject will be treated per dose level. The accelerated phase will end when the first instance of moderate toxicity (MT) attributed to $\mathrm{T}$ cell reactivity at any dose level is observed. The cohort at the current dose level will be expanded and the standard $3+3$ phase will ensue for all subsequent cohorts.

\section{The accelerated escalation phase}

Consists of one cohort, divided into 3 subcohorts of 1 subject per dose level (Cohorts $1 \mathrm{~A}, 1 \mathrm{~B}$, and $1 \mathrm{C}$ ). CAR-T cells will be given to lymphodepleted subjects by a single intravenous infusion on Day 0. Three dose levels will be 
tested, starting at 3 million CAR-T cells; followed by 10 million CAR-T cells; with the final cohort receiving 30 million CAR-T cells. All doses are $+/-20 \%$, and at least $10 \%$ of $\mathrm{T}$ cells in the preparation must be CAR-positive to meet release criteria. In a lymphopenic host, adoptively transferred $\mathrm{T}$ cells (including CAR-T cells) are expected to expand exponentially until homeostatic restoration of the T cell counts. To contain the exponential expansion of CAR-T cells and maximize safety, one billion autologous untransduced peripheral blood lymphocytes (PBL) will be administered intravenously on Day 2 to all subjects in the accelerated escalation phase (cohort $1 \mathrm{~A}, 1 \mathrm{~B}$, and $1 \mathrm{C}$ ). Additional safety benefits will be derived by the significantly shortened lymphopenia under this design.

\section{The standard escalation phase}

Consists of 4 cohorts, each comprising 3 patients per dose level. To maximize safety, CAR-T cells will be dosed using a "split-dose" approach to the intravenous infusion: $10 \%$ on Day $0,30 \%$ on Day 1 and $60 \%$ on Day 2. Four dose levels will be given, from 100 million to 1 billion CAR-T cells. Again, to prevent the population of CAR-T cells from expanding excessively, subjects will be administered untransduced PBL in a "decrescendo" dose scheme: cohort 2 will receive 100 million CAR-T cells followed by 1 billion PBL; cohort 3 will receive 300 million CAR-T cells followed by 700 million PBL; cohorts 4 and 5 will recieve 300 million and 1 billion CAR-T cells, respectively, without any PBL (Figure 2).

\section{Regimen}

At entry, subjects will be screened and their eligibility will be determined. Those who meet all eligibility criteria will undergo apheresis within 4-6 weeks prior to the Day 0 visit, in order to obtain peripheral blood mononuclear cells (PBMCs) for CAR-T cell manufacturing. PBL will be enriched by a process of elutriation [36]; transduced with anti-FR- $\alpha$ scFv CAR; expanded in vitro; and then frozen for future administration. Subjects will be allowed to undergo standard of care therapy at the discretion of the investigator while CAR-T cells are being manufactured, if clinically indicated due to rapid disease progression.

Subjects will be enrolled serially, with a minimum of four weeks elapsing between dosing the last subject of one dose level to dosing the first subject at the next dose level. In each cohort, a minimum of three weeks must elapse (for evaluation of toxicities) after each subject starts treatment prior to the next subcohort/subject.

Subjects will receive a single course of outpatient lymphodepleting chemotherapy with intravenous cyclophosphamide $(300 \mathrm{mg} / \mathrm{m} \mathrm{[2]/d}$ for 3 consecutive days) and intravenous fludarabine $(30 \mathrm{mg} / \mathrm{m} \quad[2] / \mathrm{d}$ for 3 consecutive days) prior to $\mathrm{T}$ cell administration. Subjects in cohort 1 will receive 3-30 million CAR-T cells dosed intravenously 1-3 days after lymphodepletion on Day 0 . Subjects in cohort 2-5 will receive 100 million to 1 billion CAR-T cells 1-3 days after lymphodepletion (on Day 0, 1 and 2), using a "split-dose" approach. Subjects in cohort 1-3 only will receive untransduced autologous PBL intravenously on Day 2. (Figure 3)

Subjects will be followed daily for the first 5 days (starting at Day 0), twice weekly until week 4 $(\sim 28$ Days) and weekly until end of study (EOS). After EOS, the interventional portion of the protocol ends and long-term follow-up (LTFU) begins. LTFU occurs semiannually for up to five years post-infusion and then annually thereafter for up to 15 years after EOS or early withdrawal.

Subjects will have an optional CT or ultrasoundguided tumor biopsy at screening, if they have detectable disease that can be safely accessed, or a needle aspiration of malignant effusion, to determine if tumor expresses FR $\alpha$. Alternatively, archived tumor tissue will be tested. All subjects will have a mandatory CT or ultrasoundguided tumor biopsy at EOS, if they have detectable disease that can be safely accessed, or a needle aspiration of malignant effusion. Subjects will have end of study 1 visit (EOS1) on $\sim$ Day 58. However, subjects with no evidence of response by conventional RECIST (response evaluation criteria in solid tumors) will be offered to undergo another CT or MRI 4-8 weeks post Day 58 to further evaluate tumor burden applying immune-related response criteria (irRC) [37] to report as a secondary endpoint.

The trial has been approved by all regulatory boards and it will be conducted in accordance with the protocol.

\section{Objectives and endpoints}

The primary objective of this study is to determine the safety and feasibility of the therapy with $\mathrm{T}$ cells stably transduced with the anti-FR $\alpha$ CAR administered intravenously following transient lymphodepletion with cyclophosphamide/fludarabine. The secondary objectives are to determine anti-tumor response using RECIST and/or irRC; to assess the distribution of immune related (ir)-progression-free survival, overall survival and time to progression; to define a no observable adverse effect level (NOAEL) or an optimal biologic dose (OBD) of FR $\alpha$ CAR-T cells; to determine the effect of CAR-T cells on tumor immunity and FR $\alpha$ expression (for patients with available pre-treatment tumor sample); determine whether circulating CAR-T cells retain antitumor effects in time; and to evaluate the engraftment of CAR-T cells in circulation longitudinally in time, and in tumors at the end of study. 


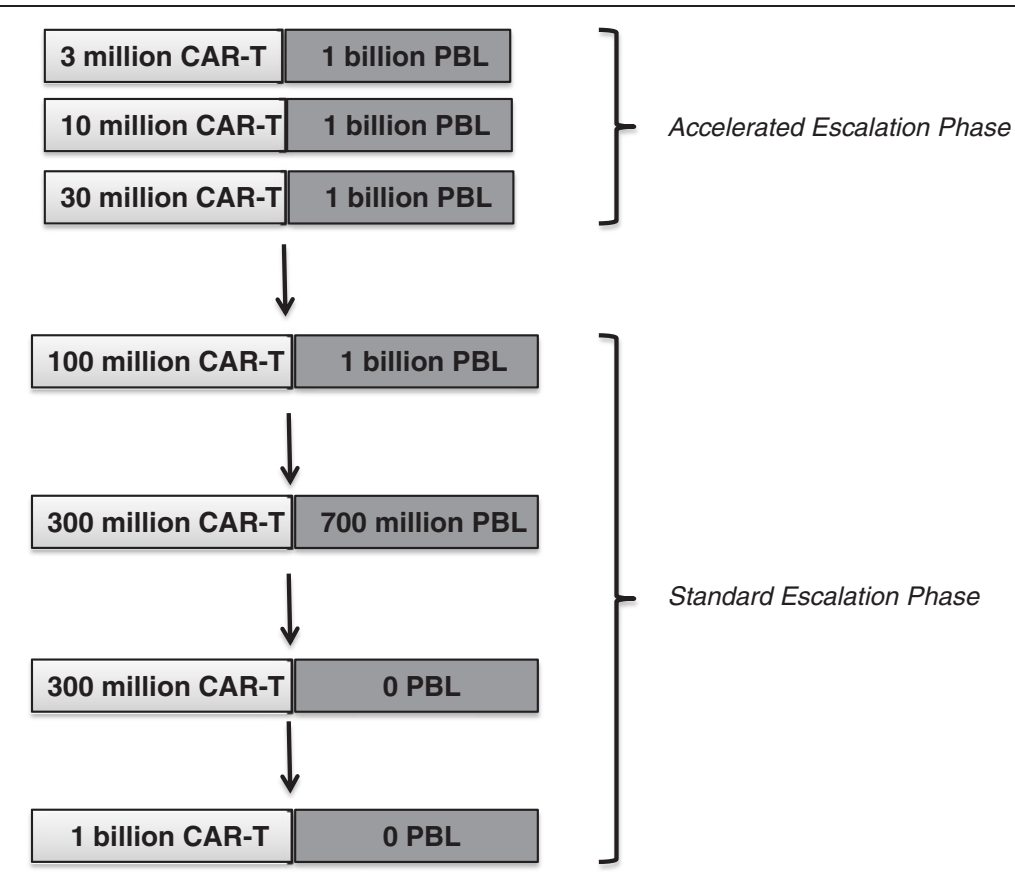

Figure 2 Clinical trial design: Dose escalation schema.

\section{Statistical methods}

This is a phase-I dose-finding study. The sample size is based on the numbers of patients needed to find the MTD and determine with 95\% confidence that the toxicity level at the MTD is less than $33 \%$. Safety of transferring T cells will be evaluated through the identification of a phase-II dose using a $3+3$ standard dose escalation design. Progression-free and overall survival will be presented graphically using the Kaplan-Meier method. Descriptive statistics will be applied to determine the relative engraftment, persistence in blood (and optionally trafficking to tumor) of the CAR-T cells. Number of CAR-T cells in blood, Human Anti-Chimeric antibody (HACA) levels, serum cytokine levels and IFN-g ELISPOT measurement of whole PBL reactivity to FR- $\alpha$ protein will be displayed graphically as a function of time.

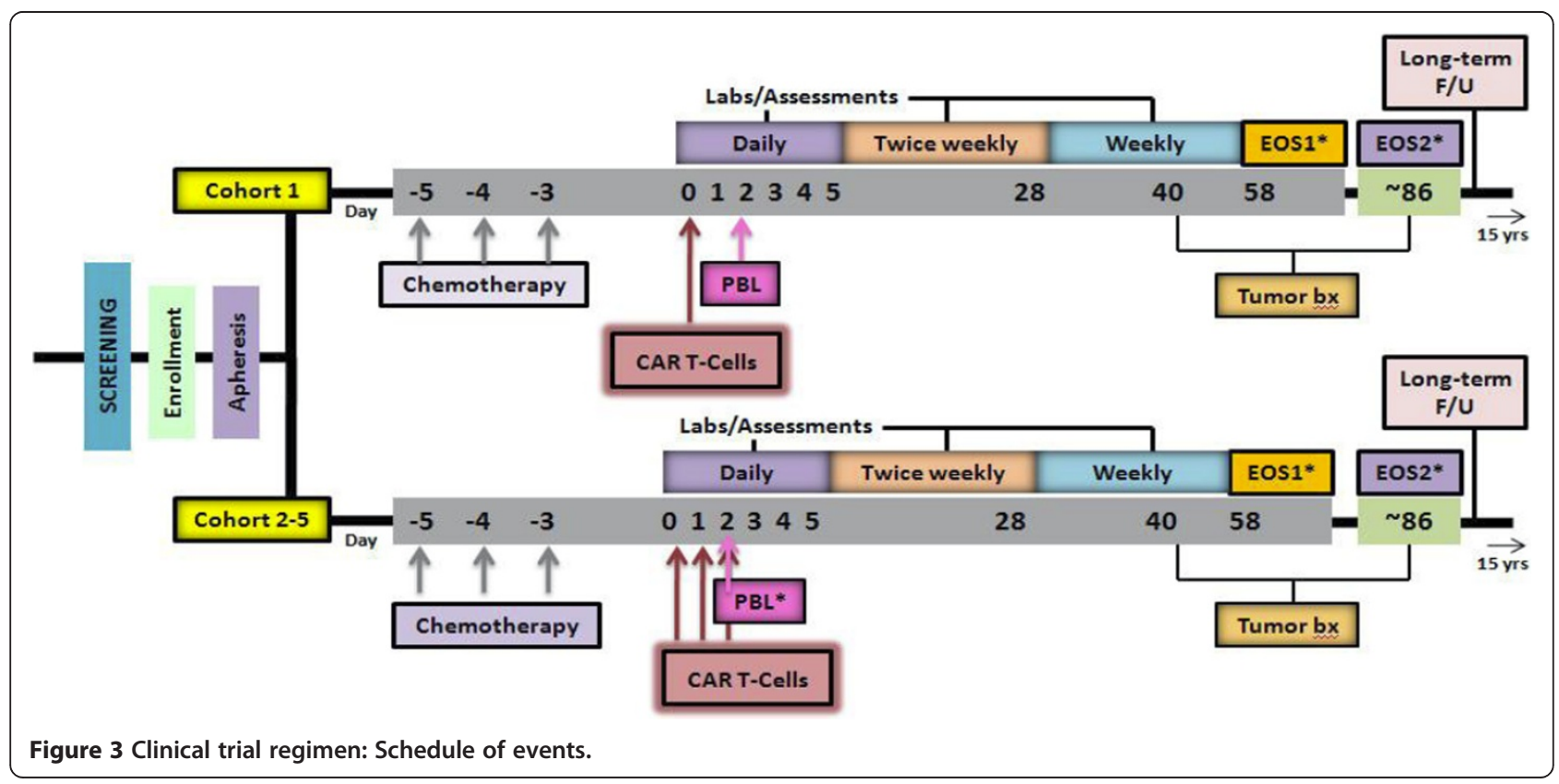




\section{Translational studies}

a) Persistence, engraftment, phenotype and function of CAR + T cells: Our main translational endpoint is to determine the fate of FR $\alpha$-directed CAR $+\mathrm{T}$ cells in vivo. Persistence of $\mathrm{T}$ cells post-transfer is a critical marker of successful engraftment and clinical efficacy [38]. Conveniently, CAR + T cells can be readily identified by flow cytometry using $\mathrm{PE}$ conjugated goat anti-mouse IgG F(ab')2 (Jackson ImmunoResearch) as well as detected by DNA quantitative (q)PCR for vector copy number in PBMC, an exquisitely sensitive method to test for persistence of CAR $+\mathrm{T}$ cells. CAR $+\mathrm{T}$ cells will be quantified in peripheral blood longitudinally ( $2 \mathrm{~h}$ post each infusion, daily on Days 49 , then weekly x 3 , every 4 weeks until Month 6 , and then every 3 months for 2 years. Relevant to $\mathrm{T}$ cell persistence, we will quantify endogenous IL-7 and IL15 serum cytokines, which have been implicated in the expansion and persistence of transferred T cells in the lymphodepleted host [39], along with a comprehensive cytokine panel using Luminex. The levels of endogenous IL-7 following our outpatient CY/FLU regimen have never been studied and results could guide decisions related to adding adjuvant cytokines (see below). CAR $+\mathrm{T}$ cells will also be phenotyped for IL-7 receptor (CD127) and IL-15 receptor alpha expression.

A second important question relates to the phenotype and function of CAR $+\mathrm{T}$ cells. Phenotypic analysis of $\mathrm{CAR}+\mathrm{T}$ cells will include detailed interrogation for memory cell markers (CCR7, CD62L, CD45RA, CD27, CD28, Fas, etc.) vs. effector cell markers (CD45R0, CCR6, CD25, CD38, HLA-DR, GITR, PD-1, etc.), and among these we will quantify CAR $+\mathrm{T}$ cells expressing inhibitory receptors suggesting exhausted phenotype (PD-1, LAG-3, TIM-3 etc.). The presence of memory $\mathrm{T}$ cells is a strong predictor of long-term persistence and efficacy in the human, and in mouse models of adoptive therapy it has been dramatically enhanced by IL-7 [40]. Phenotypic analysis will be paired with functional analysis; whole PBL or enriched CAR + T cells will be coincubated with ovarian cancer cells expressing $\mathrm{FR} \alpha$, or stimulated with PHA-ionomycin, FR $\alpha$ protein or CD3/ CD28 beads as control, followed by interrogation of intracellular cytokines (INF- $\gamma$, TNF- $\alpha$, MIP-1 $\alpha$, IL-2, IL17, IL-4, TGF- $\beta$, IL-10), granzymes, CD137 and CD107a. These will provide a detailed longitudinal characterization of in vivo $\mathrm{T}$ cell polarization and function posttransfer. Based on mouse data, we expect these cells to maintain a Th1 polarization, but it is possible that with time they exhibit an exhausted phenotype and function (PD-1+, unable to proliferate and with reduced IL-2 or
TNF- $\alpha$ upregulation). These findings will guide future clinical development. Lastly, the presence of CAR $+\mathrm{T}$ cells will be quantified in tumor biopsies by DNA qPCR and correlated with tumor FR $\alpha$ protein expression at baseline and end of study.

b) CAR immunogenicity: We will assess the development of host immune responses to the CAR T cells by HAMA, HACA and VSV-G ELISA, and correlate with engraftment of CAR $+\mathrm{T}$ cells. These results will guide the need for future development of a CAR bearing a human anti- FR $\alpha$ scFv.

\section{Innovation}

This trial introduces several innovations: First, although, a previous CAR against FR $\alpha$ has been tested, this CAR introduces the potent costimulatory domain of 4-1BB. Second, the previous construct utilized a retrovirus, while this CAR is introduced via a lentivirus. Finally, unlike the previous trial, this trial will use cytotoxic chemotherapy to induce transient lymphodepletion. The proposed therapeutic approach is novel and has not been previously tested. In addition to these technological innovations that take advantage of advances made over the past 10 years $[22,35,41]$, this trial is introducing a novel adoptive $\mathrm{T}$ cell therapy design that tries to maximize safety and minimize untoward acute effects, as well as, adverse events from uncontrolled long-term expansion of CAR-T cells that are infused following lymphodepletion.

CAR-T cells may induce acute infusion reactions and pathological cytokine responses. On-target acute toxicity has been observed in some trials using CAR-T cells. A patient treated with $\mathrm{T}$ cells bearing a Her2/neu-specific CAR: CD28-CD137- $\zeta$ died soon after adoptive transfer, probably due to rapid hyperactivation induced by the recognition of normal tissue expressing the same antigen [42]. Moreover, another patient died after preconditioning and adoptive transfer of $\mathrm{T}$ cells bearing a CD19-specific CAR:CD28- $\zeta$, although, in this case an underlying infection released due to the cyclophosphamide preconditioning regimen was the most probable cause of this mortality [43]. To mitigate these risks we introduced two safety measures: a) Subjects will receive incrementing doses of CAR-T cells with the first cohort starting at an unusually low dose of 3 million $T$ cells, and we will escalate doses by half log increments. b) CAR-T cells will be dosed using a "split-dose" approach to the intravenous infusion: $10 \%$ on Day $0,30 \%$ on Day 1 and $60 \%$ on Day 2 .

Furthermore, CAR-T cells may initiate autoimmune attack on normal tissues if their target is expressed in vital organs and a critical number of self-reactive $\mathrm{T}$ cells is reached. Examples of such self-recognition include myocarditis, nephritis, hepatitis or colitis. Although, in the proposed trial we will start at a very low dose of CAR-T 
cells, these are expected to expand exponentially in the lymphodepleted host and eventually they could reach a critical mass sufficient for auto-reactivity. Indeed, in the absence of any additional manipulation, the frequency of CAR-T cells may remain unaltered as adoptive T cells repopulate the host. When Porter and colleagues infused a low dose $(1.5 \times 10$ [5] cells per kilogram of body weight) of autologous anti-CD19 CAR-T cells in a patient with CLL, these cells expanded over 3 weeks to a level that was more than 1,000 times as high as the initial engraftment level in vivo. This patient experienced development of tumor lysis syndrome only after CAR-T cells reached a critical threshold several weeks after $\mathrm{T}$ cell transfer, and finally complete remission was achieved. These engineered cells persisted at high levels for 6 months in the blood and the bone marrow and continued to express the chimeric antigen receptor.

To maintain a low frequency of CAR-T cells in the repopulated host, we introduced a design whereby after uncontrolled expansion of CAR-T cells is allowed for 48 hours, a bulk of untransduced autologous PBL is infused. Accordingly, subjects in the accelerated escalation phase (cohort 1) will receive one billion autologous untransduced PBL. To permit incremental expansion of CAR-T cells, subsequent cohorts will receive "decrescendo" untransduced PBL (1 billion, 700 million and none). The innovation lying behind the inclusion of untransduced PBL introduces a middle ground between completely lymphodepleting the host, whereby all space is made available for the proliferating CAR-T cells to occupy by expansion (leading to possible delayed toxicity), and infusing CAR-T cell in a non-depleted host, giving them no room to expand and thus likely limiting their therapeutic potential (Figure 4). If toxicity is still seen despite the above safety measures, CAR-T cells could also be controlled with corticosteroids and/or immunosuppressive drugs [44].

\section{Discussion}

With compelling evidence that ovarian cancers are immunogenic tumors [45] and with the dramatic advances in laboratory and clinical procedures, new opportunities have been created for ovarian cancer immunotherapy $[46,47]$. In order to be effective, cancer immunotherapy is dependent on the presence of sufficient numbers of antitumor lymphocytes with appropriate homing and effector functions that enable them to seek out and destroy cancer cells in vivo. The adoptive transfer of ex vivo expanded, tumor-reactive $\mathrm{T}$ cells holds the potential of achieving this condition in a short period of time. However, adoptive $\mathrm{T}$ cell immunotherapeutic strategies utilizing naturally-occurring tumor-reactive $\mathrm{T}$ cells are limited by the availability of such $\mathrm{T}$ cells for administration and the downregulation of MHC class I molecules and antigen processing machinery by the tumor [48]. To obviate these obstacles CAR-T cells were designed to redirect the anti-tumor immune response to FR $\alpha$ expressed on the surface of ovarian cancer cells.

The objective of this study is to implement adoptive transfer of FR $\alpha$ CAR-T cells following transient

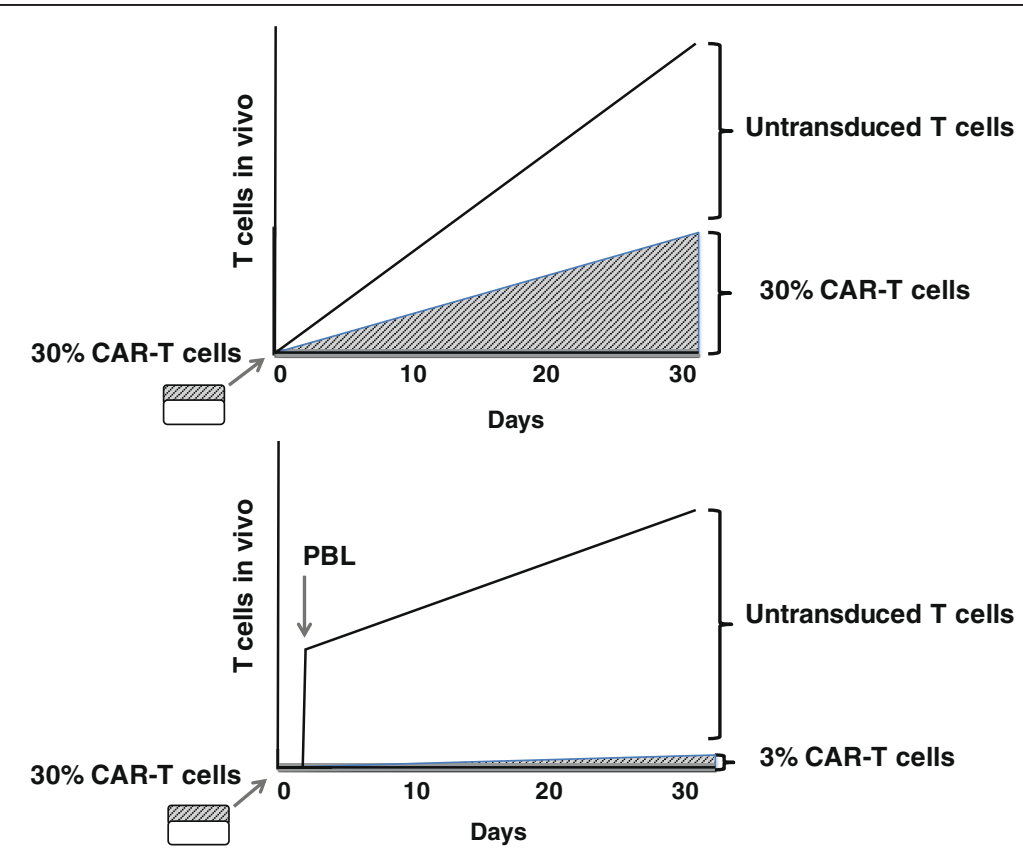

Figure 4 Modeling of CAR-T cell expansion in vivo in the lymphodepleted host without (above) and with (below) infusion of bulk untransduced PBL on Day 2. 
lymphodepletion with cyclophosphamide/fludarabine and evaluate the safety and feasibility of this treatment for recurrent ovarian cancer patients. The ultimate goal of this approach is to induce tumor-specific immune response in patients with FR $\alpha$-positive ovarian cancer and achieve a prolongation of progression-free survival in patients with a recurrent disease who otherwise do not respond to other therapies. We chose folate receptor as the target antigen because it is expressed at high levels in $90 \%$ of epithelial ovarian carcinoma [49], its expression is not significantly altered even after chemotherapy [50], and because it appears to be a safe target [33].

To successfully apply CAR-T cells in the clinic, transient lymphodepletion is necessary to create a favorable space and environment for the efficient expansion and activation of CAR-T cells. Lymphodepletion has many attributes such as reduction in the number of immunosuppressive regulatory $\mathrm{T}$ cells and enhancement of the half-life and effectiveness of adoptive T cell therapy [47]. Lymphodepletion also enhances transiently the availability of cytokines such as IL-7 and IL-15 [51]. The benefits of transient lymphodepletion prior to cell infusion are observed in an ongoing trial at the University of Pennsylvania where patients with myeloma who received autologous CD3/CD28-costimulated $\mathrm{T}$ cells 2 days after Busulfan showed improved engraftment compared to patients where $\mathrm{T}$ cells were given 12 days after chemotherapy $[52,53]$.

We will also apply certain safety measures to mitigate the risks associated with this powerful therapy. We will start with a very low dose of CAR-T cells; we will administer higher doses in an incremental split-dose approach; and finally, we will infuse a large number of autologous PBLs two days after the CAR-T-infusion to suppress the potential overexpansion of CAR-T cells and to provide a safety mechanism.

We expect that FR $\alpha$-specific CAR-T cells will persist in circulation for prolonged periods of time, just as it was seen in recent CD19 CAR trials. This will be evaluated using the same molecular methods, including flow cytometry and RT-PCR used previously [54]. However, it is possible that in the CD19 CAR trials, long persistence of CAR-T cells was allowed by the absence of HAMA due to the complete ablation of $\mathrm{B}$ cells, which ensued CD19 CAR-T cell therapy, as well as chronic antigen stimulation provided by ever emergent $\mathrm{B}$ cells arising from the bone marrow and attempting to reconstitute the host. In the proposed trial, the B cell compartment will be intact and HAMA [55] could develop and shorten the half-life of our FR $\alpha$ CAR-T cells. In that case, using a human $\mathrm{scFv}$ in the redesign of the CAR will be crucial to enable long-term engraftment of CAR-T cells.

We expect that the adoptively transferred CAR-T cells will traffic to the ovarian tumors deposits and will mediate regression of the cancer cells. Lymphocytes have complex trafficking and survival kinetics, but based on previous data from a trial with CAR-T cells at the University of Pennsylvania [22] we anticipate that the halflife of CAR-T cell following single infusion will be longer than that of normal CD8+ cells (half-life of normal CD8 + cells is 10 days) and that this therapy will provide a long lasting effect. Unlike antibody-mediated therapy, CAR-modified $\mathrm{T}$ cells have the potential to replicate and survive in vivo, and long-term presence could lead to sustained tumor control.

In summary, we hypothesize that the clinical efficacy of the proposed CAR-T cell regimen following transient lymphodepletion will be substantial and that the potential benefits outweigh the risks. CAR-T cells have been administered in patients with different types of tumors in different phase I trials. When patients with CLL were treated with CAR-T cells, the cell infusions had no acute toxic effects and the engineered cells persisted at high levels for 6 months in the blood and bone marrow and continued to express the CAR. If a lack of dose-limiting toxicities is confirmed in the present study, we will test whether exogenous cytokine support (e.g. IL-7) can enhance CAR-transduced $\mathrm{T}$ cell persistence and expand a CAR-transduced memory $\mathrm{T}$ cell population in vivo following adoptive transfer. A positive outcome from CAR$\mathrm{T}$ therapy trials in terms of effective therapy, extension of progression free and overall survival in a recurrent setting would represent a major advancement for patients with advanced ovarian cancer.

\section{Abbreviations}

CAR-T cell: Chimeric antigen receptor-expressing T cell; DLT: Dose limiting toxicity; ECOG: Eastern Cooperative Oncology Group; EOC: Epithelial ovarian cancer; EOS: End of study; FRa: Folate receptor-alpha; HAMA: Human antimouse antibody; irRC: Immune response related criteria; MHC: Major histocompatibility antigen; MTD: Moderate toxicity dose; NOAEL: No observable adverse effect level; OBD: Optimal biologic dose; PBL: Peripheral blood leukocytes; PET: Positron emission tomography; RECIST: Response evaluation criteria in solid tumors; scFv: Single chain variable fragment; TCR: T cell receptor; TIL: Tumor infiltrating lymphocytes; Treg: Regulatory T cell.

\section{Competing interests}

The authors declare that they have no competing interests.

\section{Authors' contribution}

DP is the IND sponsor for the clinical study and was responsible for the construction and preclinical evaluation of the AFR CAR and contributed to the study design. GC and LK designed the clinical study and wrote the manuscript. All authors read and approved the final manuscript.

\section{Acknowledgement}

We thank Klara Balint for her help during the preparation of this manuscript We acknowledge Ovarian Cancer Research Fund for their support.

Received: 25 June 2012 Accepted: 18 July 2012

Published: 3 August 2012

\section{References}

1. Jemal A, Bray F, Center MM, Ferlay J, Ward E, Forman D: Global cancer statistics. CA Cancer J Clin 2011, 61:69-90. 
2. Bukowski RM, Ozols RF, Markman M: The management of recurrent ovarian cancer. Semin Oncol 2007, 34:S1-S15.

3. Morgan RJ Jr, Alvarez RD, Armstrong DK, Chen LM, Copeland L, Fowler J, Gaffney DK, Gershenson D, Greer BE, Johnston C, Lancaster JM, Lele S, Matulonis U, Ozols RF, Remmenga SW, Sabbatini P, Soper J, Teng N: Ovarian cancer. Clinical practice guidelines in oncology. J Nat/ Compr Canc Netw 2006, 4:912-939.

4. Ozols RF: Challenges for chemotherapy in ovarian cancer. Ann Oncol 2006, 17(Suppl 5):v181-v187.

5. Chu CS, Kim SH, June $\mathrm{CH}$, Coukos G: Immunotherapy opportunities in ovarian cancer. Expert Rev Anticancer Ther 2008, 8:243-257.

6. June CH: Adoptive T cell therapy for cancer in the clinic. J Clin Invest 2007, 117:1466-1476.

7. Fujita K, Ikarashi H, Takakuwa K, Kodama S, Tokunaga A, Takahashi T, Tanaka $K:$ Prolonged disease-free period in patients with advanced epithelial ovarian cancer after adoptive transfer of tumor-infiltrating lymphocytes. Clin Cancer Res 1995, 1:501-507.

8. Aoki Y, Takakuwa K, Kodama S, Tanaka K, Takahashi M, Tokunaga A, Takahashi T: Use of adoptive transfer of tumor-infiltrating lymphocytes alone or in combination with cisplatin-containing chemotherapy in patients with epithelial ovarian cancer. Cancer Res 1991, 51:1934-1939.

9. June CH: Principles of adoptive T cell cancer therapy. J Clin Invest 2007, 117:1204-1212.

10. Theobald M, Biggs J, Hernandez J, Lustgarten J, Labadie C, Sherman LA: Tolerance to p53 by A2.1-restricted cytotoxic T lymphocytes. J Exp Med 1997, 185:833-841

11. Molldrem JJ, Lee PP, Kant S, Wieder E, Jiang W, Lu S, Wang C, Davis MM: Chronic myelogenous leukemia shapes host immunity by selective deletion of high-avidity leukemia-specific T cells. J Clin Invest 2003, 111:639-647.

12. Kessels HW, Wolkers MC, Schumacher TN: Adoptive transfer of T-cell immunity. Trends Immunol 2002, 23:264-269.

13. Clay TM, Morse M, Lyerly HK: Redirecting cytotoxic T lymphocyte responses with T-cell receptor transgenes. Expert Opin Biol Ther 2002, 2:353-360.

14. Sadelain $M$, Riviere I, Brentjens R: Targeting tumours with genetically enhanced T lymphocytes. Nat Rev Cancer 2003, 3:35-45.

15. Gabert J, Langlet C, Zamoyska R, Parnes JR, Schmitt-Verhulst AM, Malissen B: Reconstitution of MHC class I specificity by transfer of the T cell receptor and Lyt-2 genes. Cell 1987, 50:545-554.

16. Saito T, Weiss A, Miller J, Norcross MA, Germain RN: Specific antigen-la activation of transfected human $\mathrm{T}$ cells expressing murine Ti alpha betahuman T3 receptor complexes. Nature 1987, 325:125-130.

17. Gross G, Waks T, Eshhar Z: Expression of immunoglobulin-T-cell receptor chimeric molecules as functional receptors with antibody-type specificity. Proc Natl Acad Sci U S A 1989, 86:10024-10028.

18. Mullaney BP, Pallavicini MG: Protein-protein interactions in hematology and phage display. Exp Hematol 2001, 29:1136-1146.

19. Pule MA, Savoldo B, Myers GD, Rossig C, Russell HV, Dotti G, Huls MH, Liu E, Gee AP, Mei Z, Yvon E, Weiss HL, Liu H, Rooney CM, Heslop HE, Brenner MK: Virus-specific $T$ cells engineered to coexpress tumor-specific receptors: persistence and antitumor activity in individuals with neuroblastoma. Nat Med 2008, 14:1264-1270

20. Louis CU, Savoldo B, Dotti G, Pule M, Yvon E, Myers GD, Rossig C, Russell HV, Diouf O, Liu E, Liu H, Wu MF, Gee AP, Mei Z, Rooney CM, Heslop HE, Brenner MK: Antitumor activity and long-term fate of chimeric antigen receptor-positive T cells in patients with neuroblastoma. Blood 2011 118:6050-6056.

21. Kalos M, Levine BL, Porter DL, Katz S, Grupp SA, Bagg A, June CH: T cells with chimeric antigen receptors have potent antitumor effects and can establish memory in patients with advanced leukemia. Sci Trans/ Med 2011, 3:95ra73

22. Porter DL, Levine BL, Kalos M, Bagg A, June CH: Chimeric antigen receptormodified T cells in chronic lymphoid leukemia. N Engl J Med 2011 365:725-733.

23. Brentjens RJ, Riviere I, Park JH, Davila ML, Wang X, Stefanski J, Taylor C, Yeh R, Bartido S, Borquez-Ojeda O, Olszewska M, Bernal Y, Pegram H, Przybylowski M, Hollyman D, Usachenko Y, Pirraglia D, Hosey J, Santos E, Halton E, Maslak P, Scheinberg D, Jurcic J, Heaney M, Heller G, Frattini M, Sadelain M: Safety and persistence of adoptively transferred autologous CD19-targeted T cells in patients with relapsed or chemotherapy refractory B-cell leukemias. Blood 2011, 118:4817-4828.
24. Kochenderfer JN, Dudley ME, Feldman SA, Wilson WH, Spaner DE, Maric I, Stetler-Stevenson M, Phan GQ, Hughes MS, Sherry RM, Yang JC, Kammula US, Devillier L, Carpenter R, Nathan DA, Morgan RA, Laurencot C, Rosenberg SA: B-cell depletion and remissions of malignancy along with cytokineassociated toxicity in a clinical trial of anti-CD19 chimeric-antigenreceptor-transduced T cells. Blood 2012, 119:2709-2720.

25. Kochenderfer JN, Wilson WH, Janik JE, Dudley ME, Stetler-Stevenson M, Feldman SA, Maric I, Raffeld M, Nathan DA, Lanier BJ, Morgan RA, Rosenberg SA: Eradication of B-lineage cells and regression of lymphoma in a patient treated with autologous $T$ cells genetically engineered to recognize CD19. Blood 2010, 116:4099-4102.

26. Kershaw MH, Westwood JA, Parker LL, Wang G, Eshhar Z, Mavroukakis SA White DE, Wunderlich JR, Canevari S, Rogers-Freezer L, Chen CC, Yang JC, Rosenberg SA, Hwu P: A phase I study on adoptive immunotherapy using gene-modified T cells for ovarian cancer. Clin Cancer Res 2006, 12:6106-6115.

27. Leamon CP, Low PS: Delivery of macromolecules into living cells: a method that exploits folate receptor endocytosis. Proc Natl Acad Sci U S A 1991, 88:5572-5576.

28. Coney LR, Tomassetti A, Carayannopoulos L, Frasca V, Kamen BA, Colnaghi MI, Zurawski VR Jr: Cloning of a tumor-associated antigen: MOv18 and MOv19 antibodies recognize a folate-binding protein. Cancer Res 1991, 51:6125-6132

29. Reddy JA, Low PS: Folate-mediated targeting of therapeutic and imaging agents to cancers. Crit Rev Ther Drug 1998, 15:587-627.

30. Xia W, Low PS: Folate-targeted therapies for cancer. J Med Chem 2010, 53:6811-6824

31. Li J, Sausville EA, Klein PJ, Morgenstern D, Leamon CP, Messmann RA, LoRusso P: Clinical pharmacokinetics and exposure-toxicity relationship of a folate-Vinca alkaloid conjugate EC145 in cancer patients. J Clin Pharmacol 2009, 49:1467-1476.

32. Sausville EA, LoRusso $P$, Quinn $M$, Forman $K$, Leamon CP, Morgenstern $D$, Bever S, Messmann RA: A Phase I Study of EC145 Administered Weeks 1 and 3 of a 4-Week Cycle in Patients with Refractory Solid Tumors. Alexandria, VA:; 2007:2577.

33. Konner JA, Bell-McGuinn KM, Sabbatini P, Hensley ML, Tew WP, PanditTaskar N, Vander Els N, Phillips MD, Schweizer C, Weil SC, Larson SM, Old LJ: Farletuzumab, a humanized monoclonal antibody against folate receptor alpha, in epithelial ovarian cancer: a phase I study. Clin Cancer Res 2010, 16:5288-5295.

34. Canevari S, Stoter G, Arienti F, Bolis G, Colnaghi MI, Di Re EM, Eggermont AM, Goey SH, Gratama JW, Lamers CH, et al: Regression of advanced ovarian carcinoma by intraperitoneal treatment with autologous $T$ lymphocytes retargeted by a bispecific monoclonal antibody. J Natl Cancer Inst 1995, 87:1463-1469.

35. Song $D G$, Ye $Q$, Carpenito C, Poussin $M$, Wang $L P$, Ji C, Figini $M$, June $C H$, Coukos G, Powell DJ Jr: In vivo persistence, tumor localization, and antitumor activity of CAR-engineered T cells is enhanced by costimulatory signaling through CD137(4-1BB). Cancer Res, 2011, 71:4617-4627.

36. Powell DJ, Brennan AL, Zheng Z, Huynh H, Cotte J, Levine BL: Efficient clinical-scale enrichment of lymphocytes for use in adoptive immunotherapy using a modified counterflow centrifugal elutriation program. Cytotherapy 2009, 11:923-935.

37. Wolchok JD, Hoos A, O'Day S, Weber JS, Hamid O, Lebbe C, Maio M, Binder M, Bohnsack O, Nichol G, Humphrey R, Hodi FS: Guidelines for the Evaluation of Immune Therapy Activity in Solid Tumors: Immune-Related Response Criteria. Clinical Cancer Research 2009, 15:7412-7420.

38. Robbins PF, Dudley ME, Wunderlich J, El-Gamil M, Li YF, Zhou J, Huang J Powell DJ, Rosenberg SA: Cutting edge: persistence of transferred lymphocyte clonotypes correlates with cancer regression in patients receiving cell transfer therapy. I Immunol 2004, 173:7125-7130.

39. Gattinoni L, Finkelstein SE, Klebanoff CA, Antony PA, Palmer DC, Spiess PJ, Hwang LN, Yu Z, Wrzesinski C, Heimann DM, Surh CD, Rosenberg SA, Restifo NP: Removal of homeostatic cytokine sinks by lymphodepletion enhances the efficacy of adoptively transferred tumor-specific CD8+ T cells. J Exp Med 2005, 202:907-912.

40. Schluns KS, Kieper WC, Jameson SC, Lefrançois L: Interleukin-7 mediates the homeostasis of naïve and memory CD8 T cells in vivo. Nat Immuno 2000, 1:426-432.

41. Dadmarz RD, Ordoubadi A, Mixon A, Thompson CO, Barracchini KC, Hijazi YM, Steller MA, Rosenberg SA, Schwartzentruber DJ: Tumor-infiltrating 
lymphocytes from human ovarian cancer patients recognize autologous tumor in an MHC class II-restricted fashion. Cancer J Sci Am 1996, 2:263-272.

42. Morgan RA, Yang JC, Kitano M, Dudley ME, Laurencot CM, Rosenberg SA: Case report of a serious adverse event following the administration of $T$ cells transduced with a chimeric antigen receptor recognizing ERBB2. Mol Ther 2010, 18:843-851.

43. Brentjens R, Yeh R, Bernal Y, Riviere I, Sadelain M: Treatment of chronic lymphocytic leukemia with genetically targeted autologous $T$ cells: case report of an unforeseen adverse event in a phase I clinical trial. Mol Ther 2010, 18:666-668.

44. Lamers CH SS, Vulto AG, Kruit WH, Kliffen M, Debets R, Gratama JW, Stoter G, Oosterwijk E: Treatment of metastatic renal cell carcinoma with autologous T-lymphocytes genetically retargeted against carbonic anhydrase IX: first clinical experience. Clin Oncol 2006, 24:e20-e22.

45. Zhang L, Conejo-Garcia JR, Katsaros D, Gimotty PA, Massobrio M, Regnani G, Makrigiannakis A, Gray H, Schlienger K, Liebman MN, Rubin SC, Coukos G: Intratumoral T cells, recurrence, and survival in epithelial ovarian cancer. N Engl J Med 2003, 348:203-213.

46. Kandalaft LE, Powell DJ Jr: Singh N, Coukos G: Immunotherapy for ovarian cancer: what's next? J Clin Oncol 2011, 29:925-933.

47. Mellman I, Coukos G, Dranoff G: Cancer immunotherapy comes of age. Nature 2011, 480:480-489.

48. Fruci D, Benevolo M, Cifaldi L, Lorenzi S, Lo Monaco E, Tremante E, Giacomini P: Major histocompatibility complex class i and tumour immuno-evasion: how to fool T cells and natural killer cells at one time. Curr Oncol 2012, 19:39-41.

49. Weitman SD, Lark RH, Coney LR, Fort DW, Frasca V, Zurawski VR, Kamen BA: Distribution of the Folate Receptor Gp38 in Normal and Malignant-Cell Lines and Tissues. Cancer Res 1992, 52:3396-3401.

50. van Dam GM, Themelis G, Crane LM, Harlaar NJ, Pleijhuis RG, Kelder W, Sarantopoulos A, de Jong JS, Arts HJ, van der Zee AG, Bart J, Low PS, Ntziachristos V: Intraoperative tumor-specific fluorescence imaging in ovarian cancer by folate receptor-alpha targeting: first in-human results. Nat Med 2011, 17:1315-1319.

51. Klebanoff CA, Khong HT, Antony PA, Palmer DC, Restifo NP: Sinks, suppressors and antigen presenters: how lymphodepletion enhances $T$ cell-mediated tumor immunotherapy. Trends Immunol 2005, 26:111-117.

52. Rapoport AP, Stadtmauer EA, Aqui N, Badros A, Cotte J, Chrisley L, Veloso E, Zheng Z, Westphal S, Mair R, Chi N, Ratterree B, Pochran MF, Natt S, Hinkle J, Sickles C, Sohal A, Ruehle K, Lynch C, Zhang L, Porter DL, Luger S, Guo C, Fang HB, Blackwelder W, Hankey K, Mann D, Edelman R, Frasch C, Levine BL, Cross A, June CH: Restoration of immunity in lymphopenic individuals with cancer by vaccination and adoptive T-cell transfer. Nat Med 2005, 11:1230-1237.

53. Rapoport AP, Grupp SA, Stadtmauer EA, Vonderheide RH, Levine BL, Fang $H B$, Yager K, Chew A, Veloso E, June CH: Rapid T cell recovery and possible auto-GVHD following adoptive transfer of ex-vivo costimulated autologous T cells at day+2 post transplant. Blood 2007, 110:236A-236A.

54. Porter DL, Kalos M, Zheng Z, Levine B, June C: Chimeric Antigen Receptor Therapy for B-cell Malignancies. J Cancer 2011, 2:331-332.

55. Oei AL, Sweep FC, Geurts-Moespot A, van Tienoven D, Von MensdorffPouilly S, Thomas CM, Massuger LF: Human anti-mouse IgM and IgG responses in ovarian cancer patients after radioimmunotherapy with 90Y-muHMFG1. Anticancer Res 2008, 28:2721-2725.

doi:10.1186/1479-5876-10-157

Cite this article as: Kandalaft et al: A phase I clinical trial of adoptive transfer of folate receptor-alpha redirected autologous T cells for recurrent ovarian cancer. Journal of Translational Medicine 2012 10:157. 